\title{
Pengaruh Metode Student Facilitator and Explaining (SFE) terhadap Kemampuan Menceritakan Kembali Isi Cerpen pada Siswa SMPN 1 Cigeulis, Pandeglang
}

\begin{tabular}{|c|c|}
\hline & $\begin{array}{c}\text { Saraswati }^{1} \\
{ }^{1} \text { Universitas Mathla'ul Anwar Banten }\end{array}$ \\
\hline ARTICLE INFO & ABSTRACT \\
\hline $\begin{array}{l}\text { Article History: } \\
\text { Received 20.07.2018 } \\
\text { Received in revised } \\
\text { form 20.08.2018 } \\
\text { Accepted 19.09.2018 } \\
\text { Available online } \\
27.09 .2018\end{array}$ & $\begin{array}{l}\text { The aim of this study is to determine the level of students' ability to retell the contents } \\
\text { of short stories by using Student Facilitator and Explaining (SFE) methods and the } \\
\text { level of students' ability in knowing the ability to retell the contents of short stories } \\
\text { with the expository method and knowing the effect of SFE methods on the ability to } \\
\text { retell the contents of short stories in class VIII students of SMPN } 1 \text { Cigeulis, } \\
\text { Pandeglang District, Academic Year 2018/2019. This study used an experimental } \\
\text { method and was conducted at SMPN } 1 \text { Cigeulis Pandeglang District Academic Year } \\
2018 / 2019 \text { by taking the eighth-grade students in academic year } 2018 / 2019 \text {. The sample } \\
\text { technique uses purposive sampling, namely class VIII A as an experimental class and } \\
\text { class VIII B as a control class. Based on the results of data processing, it was obtained } \\
\text { an illustration that the ability to retell the contents of short stories using the Student } \\
\text { facilitator end explaining method in class VIII of SMPN } 1 \text { Cigeulis Pandeglang District } \\
\text { in academic year 2018/2019 was very good. These results show that the average ability } \\
\text { is } 63.6 \text { while students who get above the average score is } 72.2 \% \text { and those who score } \\
\text { below the average of } 34.4 \% \text { of the highest score of } 80 \text {, and the lowest score of } 45 \text {. While } \\
\text { the ability to retell the contents of short stories using the expository method is still } \\
\text { lacking, it is shown that the average learning outcomes are } 53.1 \text { while students get } \\
\text { above the average is } 73.3 \% \text { and those who get a score below average } 30 \% \text { from the } \\
\text { highest score of } 70 \text { and the lowest value of } 35 \text {. From the calculation of statistics } \\
\text { obtained the results of hypothesis testing (t-test) with a significant level of } 5 \% \text { that is t } \\
\text { count greater t table } 7.332 \text {. It shows that there are differences in the ability to retell the } \\
\text { contents of short stories that use the SFE methods to obtain higher learning outcomes } \\
\text { when compared to using the expository method. }\end{array}$ \\
\hline & Keywords: Retell the Content, SFE Method. \\
\hline
\end{tabular}

DOI: $10.30653 / 006.201811 .5$

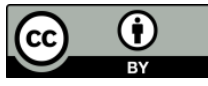

This is an open access article distributed under the terms of the Creative Commons Attribution 4.0 International License, which permits unrestricted use, distribution, and reproduction in any medium, provided the original work is properly cited. (c) 2018 Saraswati.

\section{PENDAHULUAN}

Kemampuan berbicara merupakan aspek penting yang harus dikuasai oleh setiap manusia karena pada dasarnya mereka harus mampu berkomunikasi dengan masyarakat lingkungan mereka tinggal sehingga terjalin komunikasi yang diharapkan. Begitu pula

${ }^{1}$ Corresponding author’s address: Universitas Mathla’ul Anwar Banten. Email: saraswatimaulana@gmail.com. 
siswa di sekolah dituntut pula untuk terampil berbahasa lisan, karena bahasa merupakan sarana atau alat untuk mengekspresiakan diri. Hal ini berarti dengan menggunakan bahasa lisan dapat mengungkapkan ide, gagasan, perasaan, atau pernyataan yang ditujukan kepada orang lain (pendengar) dengan menggunakan bahasa yang baik serta sesuai dengan kemampuan yang dimiliki dan dapat dimengerti oleh orang yang menjadi pendengarnya. Menurut Tarigan (2004: 21) "Pengetahuan mengenai teori berbicara akan sangat bermanfaat dan menunjang kemahiran serta keberhasilan seni dan praktek berbicara". Itulah sebabnya diperlukan pendidikan berbicara.

Kemampuan berbicara dipelajari dalam dunia pendidikan. Dunia pendidikan memberikan keterampilan-keterampilan untuk menunjang kemahiran siswa dalam berbicara. Akan tetapi pada kenyataannya, banyak siswa yang tidak mampu berbicara dengan baik. Seperti kefasihan ucapan, artikulasi yang kurang jelas serta intonasi yang tidak terdengar atau kelantangan berbicara. Selain itu, banyak siswa yang tidak berani berbicara di depan kelas atau menyampaikan ide kepada temannya. Hal ini dapat menghambat proses belajar siswa, yang berujung kepada kegagalan dalam proses pembelajaran.

Faktor-faktor yang berhubungan dengan kemampuan berbicara di antaranya adalah faktor guru yang memberikan pemahaman kepada siswa, faktor kecerdasan siswa, faktor minat siswa membaca dan faktor lingkungan keluarga. Faktor-faktor tersebut memiliki kecenderungan bahwa guru mempunyai pengaruh besar terhadap keberhasilan siswa dalam menguasai keterampilan berbicara. Kemampuan guru dalam memilih metode serta teknik mengajar yang tepat dapat mempengaruhi keberhasilan siswa dalam mengusai keterampilan berbicara.

Saat ini perlu adanya perubahan paradigma mengenai pembelajaran bahasa Indonesia. Banyak guru yang menjadikan siswa sebagai pendengar yang pasif. Artinya, pembelajaran hanya dipusatkan pada satu arah tanpa adanya timbal balik dari siswa. Semestinya pembelajaran berpusat kepada siswa, guru hanya sebagai fasilitator dalam proses pembelajaran. Siswa bukan kertas putih yang bisa diisi dengan muatan yang tidak sesuai, yang dianggap penting oleh guru. Siswa dapat dengan leluasa menggunakan kemampuan yang dimilikinya untuk memahami pelajaran. Bahkan siswa dapat menjadi guru sebaya terhadap siswa yang lainnya.

Kejenuhan siswa dalam belajar bahasa Indonesia dapat di atasi dengan cara menggunakan metode pembelajaran dalam proses pelajaran. Metode pembelajaran yang baik akan mendapatkan hasil belajar yang baik pula dan metode yang kurang sesuai akan menghasilkan hasil belajar yang kurang maksimal. Dalam melatih berbicara, guru juga bisa melatihnya dengan menceritakan isi bacaan.

Selanjutnya pemilihan bahan bacaan yang lebih mudah dicerna dapat dijadikan alternatif untuk meningkatkan kemampuan berbicara siswa salah satunya adalah sastra yang merupakan bentuk hasil karya manusia dalam wujud keindahaan/seni adalah sastra seperti cerpen, roman, novel dan lain-lain. Menyadari akan arti pentingnya cerpen dalam berbahasa, maka cerpen dijadikan bagian dari materi penting dalam pembelajaran mata pelajaran bahasa Indonesia dari tingkat pendidikan dasar hingga sekolah menengah (SMA).

Di antara karya sastra fiksi, cerpen merupakan salah satu karya sastra fiksi pada umumnya yang pertama-tama menarik perhatian orang adalah ceritanya sebagai sebuah karya imajiner dan estetik.Karya fiksi, adalah suatu karya yang menceritakan sesuatu yang bersifat rekaan, khayalan, sesuatu yang tidak ada dan terjadi sungguh-sungguh sehingga 
ia tak perlu dicari kebenarannya pada dunia nyata. Terkadang prosa naratif yang bersifat imajinatif, namun biasanya masuk akal dan mengandung kebenaran yang mendramatisasikan hubungan-hubungan antar manusia dilihat dari pengalaman dan pengamatannya terhadap kehidupan.

Cerpen (short story) merupakan bentuk karya sastra yang sekaligus disebut fiksi cerpen sebenarnya sudah banyak diketahui dan bahkan sering dinikmati oleh banyak orang.Namun, para ahli memberikan definisi dan batasan yang berbeda-beda.Marahimin (2003:113) menyatakan bahwa "cerita pendek adalah cerita rekaan yang pendek.Seperti yang disiratkan namanya, cerpen itu memang pendek, dan singkat". Jadi sebuah cerita yang pendek belum tentu dapat digolongkan ke dalam jenis cerita pendek, jika ruang lingkup yang permasalahannya yang diungkapkan tidak memenuhi persyaratan yang dituntut oleh cerita pendek. Selanjutnya Sukada (2007:10) menambahkan bahwa "cerita pendekadalah sebuah karangan yang menceritakan tentang suatu alur cerita yang memiliki tokoh cerita dan situasi cerita terbatas. Sebuah cerpen biasanya akan langsung mengarah ke topik utama cerita karena memang alur ceritanya cuma sekali dan langsung tamat". Dari pendapat Sukada dapat dimaknai sebuah cerita pendek senantiasa hanya akan memusatkan perhatiannya pada tokoh utama dan permasalahannya yang paling menonjol dan menjadi pokok cerita dalam alur yang hanya sekali dan langsung tamat.

Ciri khas cerita pendek adalah ia biasanya akan terbaca habis hanya dalam sekali duduk. Cerpen cenderung membatasi diri pada rentang waktu yang pendek, ketimbang menunjukkan adanya perkembangan dan kematangan watak pada diri tokoh.Ia lebih tertarik pada penonjolan atau eksploitasi saat-saat kritis revelasi, baik internal maupun eksternal. Cerpen jarang menggunakan plot kompleks karena sekali lagi, ia lebih terfokus pada satu episode atau situasi tertentu saja, dari pada rangkaian peristiwa.

Pada hakikatnya cerpen merupakan sebuah karya fiksi yang menyuguhkan kebenaran yang diciptakan, dipadatkan, digayakan, dan diperkokoh oleh kemampuan imajinasinya pengarang. Berdasarkan beberapa pendapat tersebut peneliti dapat menyimpulkan bahwa cerita pendek adalah cerita fiksi yang bentuknya pendek dan ruang lingkup permasalahannya menyuguhkan sebagian kecil saja dari kehidupan tokoh dan banyak dibuat oleh orang serta keseluruhan cerita memberi kesan tunggal.

Salah satu pembelajaran bahasa dan sastra yang harus dikuasai siswa adalah menceritakan kembali isi cerpen. Menceritakan kembali merupakankelanjutan dari keterampilan berbicara dalampembelajaranmelanjutkan cerita.Menceritakan kembali isi cerpen yang telah dibacakan secara lisan merupakan salah satu keterampilan berkomunikasi yang perlu dilatih, karena berbicara merupakan aspek berbahasa yang rumit dan kompleks tingkatannya. Serta menyangkut kemampuan yang lebih khusus dalam pemakaian kalimat yang efektif dan penggunaan diksi atau pilihan kata.

Menceritakan kembali isi cerita pendek merupakan pembelajaran berbicara sastra. Pembelajaran tersebut sesuai dengan kompetensi dasarnya siswa diarahkan untuk terampil berbicara sekaligus melakukan apresiasi sastra. Memahami sebuah cerita pendek diperlukan pemahaman-pemahaman terhadap tokoh, alur, konflik, setting, sudut pandang, dan gaya bahasa. Sementara itu untuk mengefektifkan berbicara disarankan agar guru memilih metode pembelajaran yang sesuai, salah satu metode yang dapat dijadikan alternatif pada pembelajaran menceritakan kembali isi cerpen adalah metode student facilitator and explaining (bermain peran).

Metode student facilitator and explaining (bermain peran) merupakan pembelajaran dimana siswa/peserta didik belajar mempresentasikan ide atau pendapat pada rekan 
peserta didik lainnya. Metode ini dilakukan dengan cara penguasaan siswa terhadap bahan-bahan pembelajran melalui imajinasi dan penghayatan yang dilakukan siswa dengan memerankan sebagai tokoh baik pada benda hidup atau benda mati. Metode ini dapat dilakukan secara individu ataupun secara kelompok. Oleh karenanya, metode ini dapat meningkatkan motivasi belajar, antusiasi, keaktifan dan rasa senang dalam belajar siswa.

Menurut Djamarah (2006: 21), dengan menggunakan metode ini dapat mempunyai nilai tambah yaitu (1) dapat dijamin jika seluruh siswa dapat berpatisipasi dan mempunyai kesempatan untuk menunjukan kemampuan dalam bekerja sama hingga berhasil, (2) dapat menambah pengalaman belajar yang menyenangkan bagi siswa. Oleh karenanya, dengan menggunakan metode ini sangat cocok jika digunakan dalam pembelajaran bahasa dengan bermain peran dapat meningkatkan kemampuan berbicara, keterampilan menyimak, keterampilan pemahaman pada teks bacaan, keterampilan pemahaman pada teks bacaan, dan keterampilan seni dalam memerankan seorang tokoh sesuai konteks bacaan.

Student facilitator and explaining (SFE) merupakan suatu kegiatan belajar kolaboratif yang dapat digunakan guru ditengah-tengah pelajaran sehingga dapat menghindari cara pengajaran yang selalu didominasi oleh guru dalam proses belajar mengajar. Melalui kegiatan belajar secara kolaborasi (bekerja sama) diharapkan peserta didik akan memperoleh pengetahuan, keterampilan, dan sikap secara aktif. Belajar aktif tidak dapat terjadi tanpa adanya partisipasi peserta didik. Terdapat berbagai cara untuk membuat proses pembelajaran yang melibatkan keaktifan siswa dan mengasah ranah kognitif, afektif, dan psikomotorik. Pada dasarnya berusaha untuk memperkuat dan memperlancar stimulus dan respons anak didik dalam pembelajaran, sehingga proses pembelajaran, sehingga proses pembelajaran menjadi hal yang menyenangkan, tidak menjadi hal yang membosankan bagi mereka.

Menurut Suprijono (2009: 128), metode pembelajaran SFE merupakan suatu metode pembelajaran di mana siswa mempresentasikan idea atau pendapat pada siswa lainnya. Metode pembelajaran ini efektif untuk melatih siswa berbicara untuk menyampaikan ide/gagasan atau pendapatnya sendiri. Pada dasarnya, agar semua metode berhasil seperti yang diharapkan pembelajaran kooperatif, setiap metode harus melibatkan materi ajar yang memungkinkan siswa saling membantu dan mendukung ketika mereka belajar materi dan bekerja saling tergantung (interdependen) untuk menyelesaikan tugas. Ketrampilan sosial yang dibutuhkan dalam usaha berkolaborasi harus dipandang penting dalam keberhasilan menyelesaikan tugas kelompok. Keterampilan ini dapat diajarkan kepada siswa dan peran siswa dapat ditentukan untuk memfasilitasi proses kelompok. Peran tersebut mungkin bermacam-macam menurut tugas, misalnya, peran pencatat (recorder), pembuat kesimpulan (summarizer), pengatur materi (material manager), atau fasilitator dan peran guru bisa sebagai pemonitor proses belajar.

Dilihat dari penerapannya, metode SFE sebagaimana diawali oleh guru memberikan pemahaman awal dan penguasaan bahan guna memberikan cakrawala berfikir tentang penghayatan dan penguasaan imajinasi bagaimana cara memerankan seorang tokoh sesuai teks yang sudah disediakan. Dengan demikian, komunikasi verbal yang ingin disampaikan kepada siswa untuk meningkatkan kemampuan berbicara dapat terealisasi dengan baik. Dari hasil pengamatan dan penilaian tersebut diharapkan siswa dapat mengungkapkan ide dan gagasannya untuk meningkatkan kemampuan berbicara tentang hal-hal yang ada dalam materi pembelajaran yang telah dibacanya kemudian siswa harus mampu menyampaikan ide gagasanya atau pendapatnya kepada peserta lain 
melalui kelompok ataupun individu terhadap pembelajaran menceritakan kembali isi cerpen tersebut.

\section{METODE}

Metode yang digunakan dalam penelitian ini adalah metode eksperimen, dengan mengambil siswa kelas VIII SMPN 1 Cigeulis tahun ajaran 2018/2019 sebagai populasi. Adapun teknik sampel menggunakan purposive sampling. Kelas yang ditentukan terdiri dari kelas VIII A sebagai kelas eksperimen berjumlah 30 siswa dan kelas VIII B sebagai kelas kontrol berjumlah 30 siswa, dengan demikian jumlah sampel dalam penelitian ini adalah 60 siswa. Kelas VIII A diberikan perlakuan menggunakan metode student facilitator and explaining selama proses pembelajaran selanjutnya kelas VIII B sebagai kelas pembanding diberikan perlakukan menggunakan metode pembelajaran langsung atau metode ekspositori selama proses pembelajaran.

\section{PEMBAHASAN}

Dalam bagian ini disajikan hasil penelitian yang mencakup deskripsi data, pengujian persyaratan analisis, data pengujian hipotesis dan pembahasan hasil penelitian.

\section{Deskripsi Data Penelitian}

Berdasarkan hasil penelitian yang diperoleh, akan dijabarkan uraian-uraian yang berhubungan dengan penelitian yaitu deskripsi data kemampuan menceritakan kembali isi cerpen dengan metode student facilitator and explaining.Hasil tes kemampuan menceritakan kembali isi cerpen diperoleh dari hasil tes kemampuan menceritakan kembali isi cerpen kemudian dari data tersebut nilai rata-rata 63,62 skor terendah 45 skor tertinggi 80 , data-data tersebut kemudian dibuat tabel distribusi dengan menggunakan rumus struges sebagai berikut.

Tabel 1. Distribusi Frekuensi Tes Kemampuan Menceritakan Kembali Isi Cerpen Kelas Eksperimen

\begin{tabular}{llllll}
\hline No & Kelas Interval & Fi & $\begin{array}{l}\text { Nilai tengah } \\
(\mathrm{Xi})\end{array}$ & Frekuensi Relatif & $\begin{array}{l}\text { Frekuensi } \\
\text { Kumulatif }\end{array}$ \\
\hline 1 & $45-50$ & 3 & 47,5 & $10,3 \%$ & $10,3 \%$ \\
\hline 2 & $51-56$ & 3 & 53,5 & $10,3 \%$ & $20,6 \%$ \\
\hline 3 & $57-62$ & 5 & 59,5 & $17,2 \%$ & $37,8 \%$ \\
\hline 4 & $63-68$ & 10 & 65,5 & $34,4 \%$ & $72,2 \%$ \\
\hline 5 & $69-74$ & 5 & 71,5 & $17,2 \%$ & $89,4 \%$ \\
\hline 6 & $75-80$ & 3 & 77,5 & $10,3 \%$ & $99,7 \%$ \\
\hline & Jumlah & 29 & - & $99,7 \%$ & \\
\hline
\end{tabular}

Berdasarkan hasil penelitian yang telah dilakukan, diperoleh data kemampuan menceritakan kembali isi cerpen dengan menggunakan metode Student facilitator and explaining sebagai berikut rata-rata 63,62, median 64,3, dan modus 65,5. Persebaran nilai kemampuan menceritakan kembali isi cerpen dapat dilihat pada Tabel 2. 
Tabel 2. Penilaian Kemampuan Menceritakan Kembali Isi Cerpen di Kelas Eksperimen

\begin{tabular}{lllll}
\hline Skor Tertinggi & Skor Terendah & Rata-rata & Median & Modus \\
\hline 80 & 45 & 63,62 & 64,3 & 65,5 \\
\hline
\end{tabular}

Selanjutnya berdasarkan hasil penelitian yang diperoleh, akan dijabarkan uraianuraian yang berhubungan dengan penelitian yaitu deskripsi data kemampuan menceritakan kembali isi cerpen dengan metode ekspositori.Hasil tes kemampuan menceritakan kembali isi cerpen diperoleh dari hasil tes kemampuan menceritakan kembali isi cerpen kemudian dari data tersebut nilai rata-rata 53,1 skor terendah 35 skor tertinggi 70, data-data tersebut kemudian dibuat tabel distribusi dengan menggunakan rumus struges sebagai berikut. Berdasarkan data di atas, maka dibuat tabel distribusi frekuensi untuk kemampuan menceritakan kembali isi cerpen dengan menggunakan metode ekspositori.

Tabel 3. Distribusi Frekuensi Tes Kemampuan Kenceritakan Kembali Isi Cerpen di Kelas Kontrol

\begin{tabular}{llllll}
\hline No & $\begin{array}{l}\text { Kelas } \\
\text { Interval }\end{array}$ & Fi & $\begin{array}{l}\text { Nilai tengah } \\
(\mathrm{Xi})\end{array}$ & $\begin{array}{l}\text { Frekuensi } \\
\text { Relatif }\end{array}$ & $\begin{array}{l}\text { Frekuensi } \\
\text { Kumulatif }\end{array}$ \\
\hline 1 & $35-40$ & 3 & 37,5 & $10 \%$ & $10 \%$ \\
\hline 2 & $41-46$ & 4 & 43,5 & $13,3 \%$ & 23,3 \\
\hline 3 & $47-52$ & 6 & 49,5 & $20 \%$ & $43,3 \%$ \\
\hline 4 & $53-58$ & 9 & 55,5 & $30 \%$ & $73,3 \%$ \\
\hline 5 & $59-64$ & 5 & 61,5 & $16,6 \%$ & $89,9 \%$ \\
\hline 6 & $65-70$ & 3 & 67,5 & $10 \%$ & $99,9 \%$ \\
\hline & Jumlah & 30 & & $99,9 \%$ & \\
\hline
\end{tabular}

Berdasarkan hasil penelitian yang telah dilakukan, diperoleh data kemampuan menceritakan kembali isi cerpen dengan menggunakan metode ekspositori sebagai berikut rata-rata 53,1, median 53,83, dan modus 55,7. Persebaran nilai kemampuan menceritakan kembali isi cerpen dapat dilihat pada Tabel 4.

Tabel 4. Penilaian Kemampuan Menceritakan Kembali Isi Cerpen Kelas Kontrol

\begin{tabular}{lllll}
\hline Skor Tertinggi & Skor Terendah & Rata-rata & Median & Modus \\
\hline 70 & 35 & 53,1 & 53,83 & 55,7 \\
\hline
\end{tabular}

\section{Pengujian Persyaratan Analisis}

Sebelum melakukan pengujian hipotesis, dilakukan uji normalitas dan homogenitas untuk kenormalan dan kehomogenan data.

\section{Uji Normalitas}

Pengujian normalitas data dilakukan dengan menggunakan chi-kuadrat dengan kriteria pengujian jika $X^{2}$ hitung $\leq X^{2}$ tabel maka data berdistribusi normal. Taraf signifikan 0,05 dengan derajat kebebasan yaitu $\mathrm{db}=\mathrm{k}-3$ dengan $\mathrm{k}$ adalah banyaknya kelas interval.Berdasarkan hasil perhitungan $X_{\text {hitung }}$ kelas eksperimen adalah 4,42 sedangkan $X^{2}{ }^{2}$ itung kelas kontrol 1,82 dengan derajat kebebasan $(\mathrm{dk})=\mathrm{k}-3=6-3=3$ tabel chi-kuadrat didapat $X_{\text {tabel }}=7,815$. Untuk lebih jelasnya dapat dilihat pada Tabel 5 . 
Tabel 5. Hasil Perhitungan Uji Normalitas

\begin{tabular}{lllll}
\hline Kelas & $\mathrm{N}$ & $X^{2}$ hitung & $X^{2}$ tabel & Kesimpulan \\
\hline Eksperimen & 29 & 4,42 & 7,815 & Normal \\
\hline Kontrol & 30 & 1,82 & 7,815 & Normal \\
\hline
\end{tabular}

Berdasarkan Tabel 5 diketahui bahwa kelas eksperimen dan kelas kontrol berdistribusi normal.

\section{Uji Homogenitas}

Langkah berikutnya adalah menguji kesamaan varians antara kelas eksperimen dan kelas kontrol atau pengujian homogenitas varians. Kriteria pengujian jika $F_{\text {hitung }} \leq \mathrm{F}_{\text {tabel, }}$ maka kedua varians bersifat homogen. Hasil perhitungan diperoleh $F_{\text {hitung }}=1,01$ dan $F_{\text {tabel }}$ $=1,03$ dengan $\mathrm{db}$ pembilang $\mathrm{n}-1=29-1=28$ dan $\mathrm{db}$ penyebut $\mathrm{n}-1=30-1=29$ dan $\alpha=$ 0,05 didapatkan $F_{\text {tabel }}=1,03$. Berdasarkan data $F_{\text {tabel }}$ diperoleh nilai 1,03 dengan demikian Fhitung $\leq F_{\text {tabel }}$ atau 1,01 $\leq 1,03$, maka kedua varians bersifat homogen. Untuk jelasnya dapat dilihat pada Tabel 6 .

Tabel 6. Hasil Perhitungan Uji Homogenitas

\begin{tabular}{llllll}
\hline Kelas & Varians & $\mathrm{N}$ & $f_{\text {hitung }}$ & $f_{\text {tabel }}$ & Kesimpulan \\
\hline Eksperimen & 63,6 & 28 & 1.01 & 1,03 & Homogen \\
\cline { 1 - 2 } Kontrol & 53,1 & 29 & & & \\
\hline
\end{tabular}

\section{Pengujian Hipotesis dan Pembahasan}

Berdasarkan uji homogenitas diketahui bahwa kedua data berdistribusi normal dan berdasarkan uji homogenitas varians menunjukan bahwa kedua sampelbersifat homogen. Maka pengujian hipotesis dapat dilakukan dengan uji kesamaan dua rata-rata melalui ujit. Kriteria pengujian pengujian sebagai berikut.

Jika thitung $>$ tabel maka Tolak $\mathrm{H}_{0}$

Jika thitung $<$ ttabel maka Terima $\mathrm{H}_{1}$

Dengan derajat kebebasan $(\mathrm{dk})=\mathrm{n}_{1}+\mathrm{n}_{2}-2$, hasil perhitungan statistik uji-t secara ringkas dapat dilihat pada Tabel 7.

Tabel 7. Hasil Uji-t Kemampuan Menceritakan Kembali Isi Cerpen

\begin{tabular}{|c|c|c|c|c|c|c|}
\hline Kelompok & Rata-rata & Dk (n-1) & $S_{i}{ }^{2}$ & fhitung & $f_{\text {tabel }}$ & Kesimpulan \\
\hline \multicolumn{7}{|l|}{ (Eksperimen) } \\
\hline $\begin{array}{lr}\text { Metode } & \text { Student } \\
\text { facilitator } & \text { and } \\
\text { explaining } & \\
\end{array}$ & 63,6 & 28 & 77,0884 & 7,332 & 2,002 & Tolak $\mathrm{H}_{0}$ \\
\hline $\begin{array}{l}\text { (Kontrol) } \\
\text { Metode Ekspositori }\end{array}$ & 53,1 & 29 & 75,8641 & & & \\
\hline
\end{tabular}

Berdasarkan Tabel 7 tampak bahwa rata-rata kemampuan menceritakan kembali isi cerpen anatara kelas eksperimen dan kelas kontrol memiliki selisish sebesar 10,5. Hal ini menunjukkan ada perbedaan yang sesungguhnya antara nilai rata-rata kelas eksperimen dan kelas kontrol, yaitu rata-rata kelas eksperimen adalah 63,6 lebih besar dari pada nilai rata-rata kelas kontrol 53,1. Perbedaan rata-rata ini memiliki harga statistik uji-t dalam 
thitung 7,332 sedangkan nilai tabel adalah 2,002 pada $\alpha=0,05$ dan derajat kebebasan $(\mathrm{dk})=\mathrm{n}_{1}$ $+\mathrm{n}_{2}-2=29+30-2=57$.

Berdasarkan hasil pengujian menunjukkan bahwa thitung sebesar 7,332 dan ttabel 2,002, ternyata memenuhi kriteria pengujian tabel $\leq$ thitung atau 2,002 $\leq 7,332$. Dengan demikian $\mathrm{H}_{0}$ ditolak dan $\mathrm{H}_{1}$ diterima pada taraf kepercayaan 0,95. Hal ini menunjukkan bahwa terdapat perbedaan yang signifikan antara kemampuan menceritakan kembali isi cerpen siswa kelompok eksperimen dengan kemampuan menceritakan kembali isi cerpen siswa kelas kontrol, artinya kemampuan menceritakan kembali isi cerpen yang menggunakan metode Student facilitator and explaining lebih tinggi dibandingkan dengan menggunakan metode ekspositori.

\section{SIMPULAN}

Berdasarkan penelitian dan hasil analisis data, penulis merumuskan beberapa simpulan bahwa kemampuan menceritakan kembali isi cerpen menggunakan metode student facilitator and explaining pada siswa kelas VIII SMPN 1 Cigeulis tahun ajaran 2018/2019 berkateori baik, hal ini terlihat dari kemampuan menceritakan kembali isi cerpen pada kelas eksperimen mendapatkan rata-rata 63,62.

Kemampuan menceritakan kembali isi cerpen menggunakan metode ekspositori pada siswa kelas VIII SMPN 1 Cigeulis tahun ajaran 2018/2019 berkategori kurang, hal ini terlihat dari kemampuan menceritakan kembali isi cerpen pada kelas kontrol mendapatkan rata-rata 53,1.

Terdapat pengaruh positif penggunaan metode student facilitator and explaining terhadap metode student facilitator and explaining pada siswa kelas VIII SMPN 1 Cigeulis tahun ajaran 2018/2019. Berdasarkan hasil uji hipotesis didapatkan dengan menggunakan uji-t pada taraf signifikan $\alpha=0,05$ thitung $=7,332$ dan harga tabel $=2,002$ dengan tingkat kesalahan $5 \%$ dan $\mathrm{dk}=57$, maka diperoleh thitung $>$ tabel dengan demikian nilai keputusannya $\mathrm{H}_{0}$ ditolak $\left(x_{1} \neq x_{2}\right)$ yang berarti secara signifikan bahwa terdapat pengaruh penggunaan metode student facilitator and explaining pada siswa kelas VIII SMPN 1 Cigeulis tahun ajaran 2018/2019.

\section{REFERENSI}

Darmono, S. D. (2009). Unsur dalam sastra. Bandung: Angkasa

Djamarah, S. B. (2004). Guru dan anak didik dalam interaksi edukatif. Jakarta: Rineka Cipta.

Hadi, S. (2008). Diktat teori sastra. Pandeglang: UNMA.

Marahimin, I. (2003). Menulis secara populer. Jakarta: Erlangga.

Nurgiantoro, B. (2003). Pengkajian teori sastra. Yogyakarta: BPEE.

Riduwan. (2010). Dasar-dasar statistik. Bandung: Alfabeta.

Suprijono, A. (2009). Cooperative learning: Teori dan aplikasi PAIKEM. Yogyakarta: Pustaka Pelajar.

Tarigan, H. G. (2004). Berbicara sebagai suatu keterampilan berbahasa. Bandung: Angkasa. 